\title{
A Rare Case Report of Prune Belly Syndrome
}

\author{
Juhee Papalkar, Deepti Shrivastava, Anuradha Kakani, Pooja Singhania
}

\begin{abstract}
Prune belly syndrome is a congenital abnormality of unknown etiology with characteristic features: Deficient development of abdominal muscles that causes the skin of the abdomen to wrinkle like a prune, cryptorchidism, abnormalities of the urinary tract. It is associated with high incidence of fetal and neonatal mortality. It can be diagnosed at 16 weeks during routine ultrasound and can be managed by fetal therapy. In rural setup women are neither visiting for routine anomaly scan nor affording for fetal therapy, hence termination of pregnancy remains the only option.
\end{abstract}

Keywords: Megacystis, Potter's facies, Prune belly.

How to cite this article: Papalkar J , Shrivastava D, Kakani A, Singhania P. A Rare Case Report of Prune Belly Syndrome. J South Asian Feder Obst Gynae 2013;5(2):83-84.

\section{Source of support $\mathrm{Nil}$}

Conflict of interest: None declared

\section{INTRODUCTION}

Prune belly syndrome is a rare, genetic, birth defect affecting about 1 in 30,000 births. ${ }^{1}$ It refers to the association of congenital dilatation of urinary tract, undescended testes and absence of anterior abdominal wall musculature. ${ }^{1}$ The deficient development of abdominal muscles causes the skin of the abdomen to wrinkle like a prune. It is associated with other congenital anomalies and most commonly clinically presented with stillborn. ${ }^{2}$

Hereby, we are presenting a rare case of prune belly syndrome diagnosed antenatally by ultrasound, hence terminated timely and proved after delivery.

\section{CASE REPORT}

A 24-year-old primigravida attended the Department of O bstetrics and Gynecology at our rural hospital on 11/04/2012 with history of amenorrhea since 7 months. She did not have any ultrasound examination for congenital anomalies earlier.

Patient was married since 1 year in a nonconsanguineous marriage and conceived spontaneously. She did not give any history suggestive of viral infections or any teratogen exposure till this gestation age. She was euthyroid, normotensive and euglycemic.

On per abdomen examination uterus was corresponding to 28 w eeks by fundal height but in spite of feeling fetal parts on pal pation cystic consistency was there. F etal heart sounds were audible in midline. On per vaginal examination head was the presenting part with cervix undilated, uneffaced tubular and posteriorly placed.

Ultrasound examination was suggestive of intrauterine live fetus of 28 weeks and cephalic presentation with dispro-

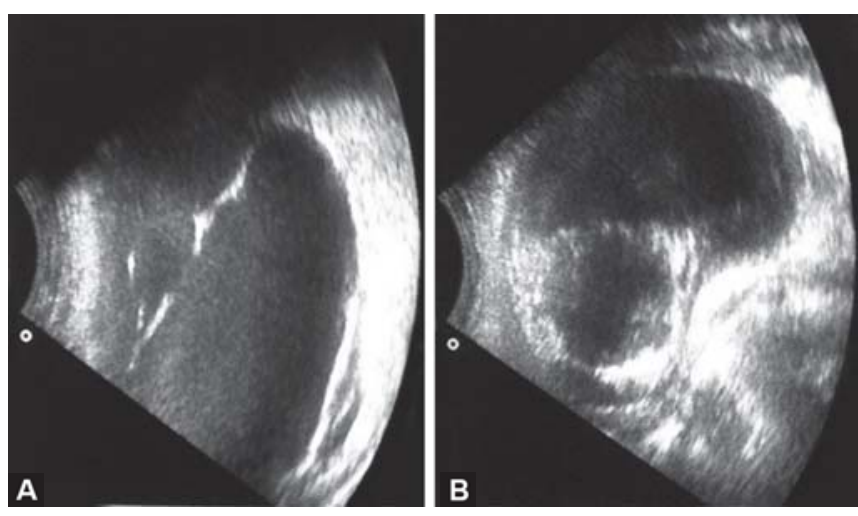

Figs 1A and B: USG plate showing antenatal scan of fetus with grossly enlarged bladder with anterior abdominal wall defect

portionately large ballooned abdomen with thinned out abdominal wall and large cystic lesion measuring $8 \times 7 \mathrm{~cm}$ which was most probably grossly dilated urinary bladder (Figs $1 A$ and $B$ ).

Only one kidney was visualized. There was evidence of severe oligohydramnios (liquor index $=0$ ). The thoracic cavity was 3 to 5 times narrower than abdominal cavity with associated pulmonary hypoplasia with high degree suspicion of prune belly syndrome.

Counseling of parents was done regarding possible prognosis of the fetus and as option of fetal therapy was not available at our center and the parents were not affordable to have it at higher center termination of pregnancy was decided.

A fter her routine investigations and coagulation profile was normal, she was induced with prostaglandin E2. A fter delivery of head there was difficulty in delivering the shoulder and abdomen. So draining of the abdominal ascites/fetal urine was done with spinal needle by vaginal route. A fter drainage of approximately $350 \mathrm{cc}$ of ascetic fluid she delivered a male still born fetus of $1.5 \mathrm{~kg}$.

Gross appearance of newborn was typical of prune belly syndrome except abdomen was still distended and did not exhibit typical wrinkles like prune. Baby had unique Potter's facies consisting of ocular hypertel orism, low-set ears, receding chin and flattening of the nose. There were absence of nipples, cystic dilatation of abdomen with deficient development of abdominal muscles, and defective insertion of umbilical cord in the anterior abdomen. The lower extremities show club feet. Scrotal skin shows little rouge. No testes in sac. The penile urethra was not clearly made out. The anal orifice was absent. On the back of baby was observed mild scoliosis (Figs 2A and $B$ ).

Drained fluid was straw colored and biochemical analysis showed presence of urea in it.

Consent for karyotyping and autopsy was denied by the relatives. 

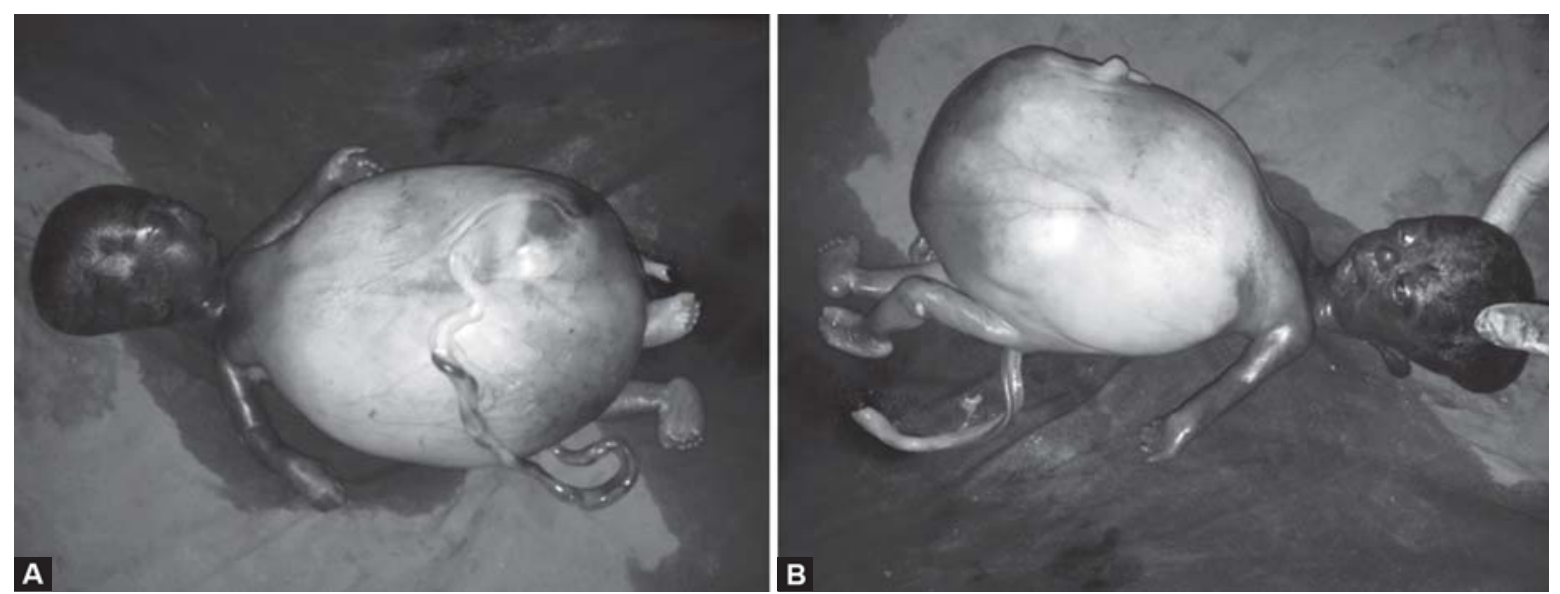

Figs 2A and B: Clinical photograph of fetus showing gross findings. (A) Characteristic Potter's facies, cystic dilatation of abdomen with wrinkles and defective insertion of umbilical cord, (B) Absence of anal opening, rudimentary scrotal sac and imperforate penis

\section{DISCUSSION}

Prune belly syndrome is named for the mass of wrinkled skin that is often (but not al ways) present on the abdomens of those with the disorder. ${ }^{1}$ Other names for the syndrome include abdominal muscle deficiency syndrome, congenital absence of the abdominal muscles, Eagle-B arrett syndrome, Obrinsky syndrome, Fröhlich syndrome, or rarely, Triad syndrome. ${ }^{3}$

$N$ inety-five percent of these cases are male. Twenty percent of the patients are still born. Thirty percent die of kidney failure within the first 2 years of life. Fifty percent have varying degrees of urinary problems. Prune belly syndrome is associated with trisomy 18 and $211^{3,4}$ Patients with prune belly syndrome also have an increased incidence of tetralogy of Fallot (TF) and ventriculoseptal defects. ${ }^{4}$

The cause of prune belly syndrome is not completely known. ${ }^{3-5}$ The histopathology of the abdominal wall muscles demonstrates a pattern of developmental arrest rather than one of atrophy. The prevailing theory is mesodermal arrest, which would explain the involvement of the genitourinary tract, the testis and the abdominal wall. Fetal ascites, which may be transient because the urine is reabsorbed before birth, may explain the abdominal wall defects.

Herniation of the bladder is prevalent in patients with prune belly syndrome because the bladder is large and redundant. Patients with urethral obstruction commonly have a patent urachus, which enables the patient to survive; early deaths usually occur in those with urethral obstruction and renal failure. ${ }^{5} \mathrm{~A}$ lthough in the literature survival of babies up to 8 to 10 years have been reported. ${ }^{6}$

\section{CONCLUSION}

Prune belly syndrome is a rare congenital disorder, commonly affecting male fetuses. The etiology is unknown but possibility of genetic inheritance is there. Antenatal diagnosis of this syndrome is important as most of the babies are either stillborn or live very short life.

Our reported case exhibited classical triad of urinary tract anomalies, deficient abdominal musculature, and bilateral cryptorchidism diagnosed on ultrasound examination but unfortunately women of rural setup come very late for routine congenital anomaly scan and availability and affordability for fetal therapy plays very important role in further management.

\section{REFERENCES}

1. Tagore KR, Ramineni A KS, L akshmi ARV , B havani N. Prunebelly syndrome. Case Report Pediatrics 2011;2011:121736.

2. Tonni $G$, A lessandro $V$, Bonasoni M P. Prune-belly syndrome: Case series and review of the literature regarding early prenatal diagnosis, epidemiology, genetic factors, treatment and prognosis. Fetal Pediatr Pathol 2013 Feb;31(1):13-24.

3. M etwalley KA, Farghalley HS, A bd-Elsayed AA. Prune belly syndrome in an Egyptian infant with Down syndrome: A case report. Journal of M edical Case Reports 2008;2:322.

4. Franco I, Chief Editor: Bradley Fields Schwartz, DO, emedicine.medscape.com/article/447619.

5. A khtar T, Alladi A, Siddappa OS. M egacystis-microcolonintestinal hypoperistal sis syndrome associated with prune belly syndrome: A case report. J Neonat Surg 2012;1:26.

6. Diao B, Diallo Y, Fall PA, Ngom G, Fall B, N doye A K, Prune B elly syndrome: Epidemiologic, clinic and therapeutic aspects. Prog U rol $2008 \mathrm{~J} \mathrm{ul;18(7):470-74.}$

\section{ABOUT THE AUTHORS}

\section{Juhee Papalkar (Corresponding Author)}

Senior Resident, Department of Obstetrics and Gynecology, J awaharlal Nehru M edical College, AVBRH, DM IMS, Wardha, M aharashtra India, Phone: 09422922915, e-mail: drjuhipapalkar@ gmail.com

\section{Deepti Shrivastava}

Professor, Department of O bstetrics and Gynecology, J awaharlal N ehru M edical College, AVBRH, DM IM S, W ardha, M aharashtra India

\section{Anuradha Kakani}

Associate Professor, Department of Obstetrics and Gynecology J awaharlal Nehru M edical College, AVBRH, DMIMS, Wardha M aharashtra, India

\section{Pooja Singhania}

Lecturer, Department of Radiology, J awaharlal N ehru M edical College, AV BRH, D M IM S, Wardha, M aharashtra, India 